\title{
CORRECTION
}

\section{Correction to: The Dababiya Quarry (southeast Luxor, Egypt): a unique palaeogeographical geosite}

\author{
R. Abd-Elhakim ${ }^{1}$ - M. A. El-Samee ${ }^{2}$ ·E. S. Sallam ${ }^{3}$
}

Published online: 16 May 2021

(c) Geologische Vereinigung e.V. (GV) 2021

\section{Correction to: International Journal of Earth Sciences https://doi.org/10.1007/s00531-020-01979-6}

In the online published article, the e-mail addresses were missed and it is now included. The e-mail addresses of the second and third authors, respectively: geo_mohamed200@ yahoo.com (M. A. El-Samee); emad.salam@fsc.bu.edu.eg (E. S. Sallam). The original article has been corrected.

The original article can be found online at https://doi.org/10.1007/ s00531-020-01979-6.

R. Abd-Elhakim

rabab_hakim78@yahoo.com

M. A. El-Samee

geo_mohamed200@yahoo.com

E. S. Sallam

emad.salam@fsc.bu.edu.eg

1 Department of Geography, Faculty of Arts, Mansoura

University, Mansoura, Egypt

2 Egyptian Environmental Affairs Agency, Cairo, Egypt

3 Department of Geology, Faculty of Science, Benha University, Banha, Egypt 